\title{
Philippe Lejeune, Écrire sa vie. Du pacte au patrimoine autobiographique
}

\section{Laura Brignoli}

\section{Q OpenEdition}

10 Journals

\section{Édition électronique}

URL : http://journals.openedition.org/studifrancesi/5439

DOI : 10.4000/studifrancesi.5439

ISSN : 2421-5856

Éditeur

Rosenberg \& Sellier

\section{Édition imprimée}

Date de publication : 1 décembre 2016

Pagination : 567

ISSN : 0039-2944

\section{Référence électronique}

Laura Brignoli, «Philippe Lejeune, Écrire sa vie. Du pacte au patrimoine autobiographique », Studi Francesi [En ligne], 180 (LX | III) | 2016, mis en ligne le 01 janvier 2017, consulté le 18 septembre 2020. URL : http://journals.openedition.org/studifrancesi/5439; DOI : https://doi.org/10.4000/studifrancesi.5439

Ce document a été généré automatiquement le 18 septembre 2020.

\section{(c) (i) (9)}

Studi Francesi è distribuita con Licenza Creative Commons Attribuzione - Non commerciale - Non opere derivate 4.0 Internazionale. 


\title{
Philippe Lejeune, Écrire sa vie. Du pacte au patrimoine autobiographique
}

\author{
Laura Brignoli
}

\section{RÉFÉRENCE}

PHILIPPE LEJEUNE, Écrire sa vie. Du pacte au patrimoine autobiographique, Paris, Mauconduit, 2015, $121 \mathrm{pp}$.

1 Né de l'exigence, vite saisie par l'éditrice, de fournir un instrument agile qui synthétise la pensée de Philippe Lejeune sur l'autobiographie, ce petit livre est aussi quelque chose d'autre. C'est d'abord le recueil de quatre conférences et une interview publiées depuis 2005 dans lesquelles l'auteur affronte son travail de différentes perspectives à partir d'une vision personnelle de son propre parcours. Son étude structurale de l'autobiographie, qui «n'est pas un texte dans lequel quelqu'un dit la vérité sur soi, mais un texte dans lequel quelqu'un de réel dit qu'il la dit» (p.17), continue avec son intérêt pour les «confessions» moins travaillées (interviews, récits oraux); il se penche ensuite sur le journal qu'il définit de la façon la plus générale possible («série de traces datées»), et lui consacre une enquête sociologique. Parallèlement à cette dernière activité il fonde l'APA, “Association pour l'autobiographie et le Patrimoine Autobiographique", qui recueillit, classe, rédige des comptes rendus de chaque manuscrit reçu (autobiographie, journal ou lettres). Les groupes de lecteurs, qui ne s'accordent aucune forme d'évaluation, devront rendre compte du ton, de l'enjeu, de la méthode et des lignes dominantes du texte, le plus souvent déposé en tapuscrit inédit, plus rarement en support informatique ou édité par un imprimeur local. Tous les deux ans l'Association publie en volume, le Garde mémoire, ces comptes rendus, soumis au préalable aux auteurs des manuscrits pour acceptation. On en a huit volumes à présent, qui rendent compte de plus de 4000 textes. Aimant les collections, ambitionnant l'exhaustivité dont il partage le goût avec Perec, Lejeune ne rebiffe pas devant l'énormité de la tâche. Entre autre, il soumet à vérification son hypothèse que les autobiographes pourraient se différencier à partir de leur religion: les protestants 
seraient plus ouverts que les catholiques, qui seraient, eux, plus secrets, alors qu'aucune donnée n'est encore disponible pour les musulmans. Mais le résultat est «une sorte d'autobiographie collective peignant sous toutes ses facettes la société française du $\mathrm{xx}^{\mathrm{e}}$ siècle» (p. 63). Des groupements thématiques sont formés, à partir des différents épisodes liés à la période 1940-45 jusqu'aux récits d'amour, au Maghreb, et d'autres groupements se formeront sans doute dans l'avenir, dans l'attente que tout cela puisse tenter, tôt ou tard, les littéraires et les linguistes.

2 Ce qui devait être un volume de synthèse devient peu à peu une sorte d'autobiographie, surtout là où l'intérêt professionnel croise les faits familiaux, comme quand Lejeune découvre les carnets de guerre de son parrain, le grand italianiste André Pézard, spécialiste de Dante, dont il met en lumière les cheminements de la pensée avant sa condensation dans l'œuvre Nous autres à Vauquois (1918).

3 Dans le dernier chapitre Lejeune s'interroge sur le futur de l'écriture du moi dans un monde bouleversé par les nouveaux moyens technologiques et constate que depuis toujours dans ce domaine «c'est l'outil qui façonne l'artisan» (p. 104). Internet expose à l'évidence le fait qu'aucun journal n'est vraiment intime, d'ailleurs Lejeune a préféré la dénomination de journal personnel puisqu'il a observé que la pratique devient vraiment populaire au moment où elle sort de l'intimité, au début du XIX siècle, pour devenir publique.

Quelqu'un a défini l'autobiographie une "subversion du féminin dans la mâle société des masques», mais, par-delà les étiquettes et les généralisations, que l'auteur luimême manie avec une extrême attention, ce qui est certain, c'est que son grand pape reste Philippe Lejeune. 